\title{
Teaching Epidemiology and Biostatistics: A Peer-Led Teaching Module for Postgraduate Psychiatry Student
}

\author{
Nicholas Tze Ping Pang, ${ }^{1,2, *}$ Eugene Koh, ${ }^{2}$ Sandi James, ${ }^{3}$ Mohd Amiruddin Mohd Kassim ${ }^{1}$
}

\section{Abstract \\ Background and Objective:}

Biostatistics and epidemiology have been integral subjects in any postgraduate courses, including medical specialties Master programs. Both are widely accepted as among the difficult and confusing subjects, which worsen by lack of adequate exposure and often, time constraints. Hence, peer-led learning approach was proposed as a viable option to the traditional lecturer-driven learning style.

\section{Method:}

The peer-led approach intends to promote targeted learning and conceptual understanding, instead of widely sweeping learning, which is rather directionless and could cause information overload.

\section{Discussion:}

Students were divided into two groups, namely humanities-inclined group and scienceinclined group. Different pedagogical methods to address the different groups were discussed.

\section{Conclusion:}

This approach helps to make the learning more palatable, boosting knowledge retention and fostering camaraderie spirit among colleagues.

Keywords: Biostatistics, postgraduate students, teaching tip, peer-led pedagogical approach

Correspondence Email: nicholas@ums.edu.my

${ }^{1}$ Faculty of Medicine and Health Science, Universiti Malaysia Sabah, Malaysia

${ }^{2}$ Universiti Putra Malaysia, 43400 Serdang, Selangor, Malaysia

${ }^{3}$ Department of Social Work and Social Policy, School of Science, Health and Engineering, La Trobe University, Australia

Received: 19/10/2020

Accepted: 15/12/2020 


\section{Introduction}

Biostatistics and epidemiology is a core part of any postgraduate curriculum with any research component. Uniquely in Malaysia, it is an especially integral part of the clinical specialist training pathway (Sidi, H. et. al., 2008). This is because in Malaysia the training pathway is structured as a four-year part time Master's degree, while providing clinical service at the same time in either university or Health Ministry hospitals, culminating with an in-course dissertation in the final year (Ahmad, Z. et. al., 1999). Unlike pure research or part research Masters Programmes, however, the clinical specialist Masters programme is especially academically taxing, as it merely has one six month in-campus training section. This is not pure classroom-driven, but rather structured as clinical service with protected teaching time (Salim, H. et. al., 2018). Due to these constraints, provision of research methodology education differs from university to university. Each university in theory will have at least ten hours of research methods training in the first year and a week-long research methodology course in the third year. However, as this can be blended into clinical work, it is difficult to have complete focus, and hence the realistic outcomes of this teaching method can be of varying quality, from complete understanding and application, to mere surface level understanding sufficient for passing written examinations only and not retained in any form subsequently (Baharudin, A. et. al., 2009). Hence, to facilitate the learning process for these difficult subjects, a peer-led driven pedagogical approach was adopted and the feedbacks were encouraging. The peer-led styles are discussed further in this article.

\section{Methods}

\section{Teaching Tip}

One way of overcoming these issues is to get "peer support" to provide education to subsequent batches. This support would be given by fellow Masters Students from senior batches that have undergone the same Masters programme and passed the examinations previously. This would be more efficacious as the knowledge would be provided by peer educators who would be more aware what aspects of research methodology were more relevant for clinical practice or dissertation preparation. The idea of peer educators is not new and has been used in various international settings (Yu, T.C. et. al., 2011). However it is more novel in a Malaysian system, perhaps due to a lecturer-driven learner style, which is reflective of "large power distance, collectivism, and high uncertainty avoidance" (Yong, F.L., 2010). However this attitude has changed in recent years in view of parallel moves towards both student-centred education and self-directed learning approaches (Spencer, J.A. et. al., 1999). Peer education and support has been increasingly viewed as a valuable and untapped teaching resource of learners assisting other learners (Cate, O.T. et. al., 2007).

Over three years, two Masters Trainees in Psychiatry gave peer-driven education about biostatistics and epidemiology to juniors in the same programme. This would be tailored to two specific requirements - exam requirements, and also topics of relevance to both actual critical appraisals in clinical practise and also towards research related requirements. 
This served the purpose of preventing directionless, overly widely sweeping learning that did not serve any practical requirements and caused information overload. Instead, learners were encouraged to do targeted learning with some assessment, clinical or research utility. This ensured information was encoded longer for potential use.

A few unique pedagogical methods were employed. One was stratification of peers into "science-inclined" and "humanities-inclined" learners, which essentially determined by method of their learning and judgement, either by primarily technical judgement or humane judgement, as well as preference to think in algorithms or the abstract aspects. This was because one of the main barriers noted in learning biostatistics and epidemiology was that a one-size-fits-all method of teaching was applied to all learners for a topic that many trainees had previously little or no exposure to. As psychiatry training programmes generally attract a large proportion of humanities-inclined doctors, traditional approach would result in poor understanding amongst them. The two groups were taught using subtly different methods, but both methods were blended during the class, and trainees could pick and choose the aspects of each method that suited them best.

For the science-inclined trainees, a method was devised where they were taught to recognise patterns and focus on core understanding of first principles of biostatistics. For instance, they were taught to derive odds ratios and relative risks from scratch rather than blindly memorising formulae. For the humanities-inclined group, overall principles were taught in a "storyline" method, categorizing study designs and associated statistical tests in order from "weak" to "strong". Any new information was always linked back to the same overarching "evolutional" model of biostatistics. This helped them see the bigger picture and form a narrative about the biostatistics they were about to learn. The shock and humour factor were also used to great effect. As biostatistics is traditionally seen as dry and difficult to remember, where possible, memorable bordering on improbable examples were used to illustrate statistical principles. Both methods were blended and mixed during each session.

For instance, instead of blindly educating about "Type I and Type II errors" - traditionally one of the most difficult subjects to master - we began with use of humorous examples. "Television is associated with lung cancer" was taught as an example of Type I error, which essentially a simple analogy to describe false positive and rejection of true null hypothesis, as television is not associated with lung cancer. Meanwhile, "Clozapine is not able to treat schizophrenia - however the study is done in 3 people" was used as an example of Type II error, which would be considered as false negative and non-rejection of false null hypothesis, as Clozapine is well known to be one of the better medicine to treat schizophrenia. Expanding on that, we then diverted into the "science-inclined" method where the method of deriving alpha and beta values was explained step by step rather than through blind formula memorisation. Subsequently, trainees from both groups were asked to provide peer-led education, by teaching what they had just learnt to each other. The science-inclined group thus helped the humanities-inclined group with the understanding of basic principles, while the humanities-inclined group helped the science-inclined group to see the bigger picture better. It was felt that trainee-driven peer teaching meant better empathy as they could identify better with each other's' weaknesses, as compared to teachers or seniors with mastery. 
This method was refined over three years with three consecutive batches of trainees, who ranged from batches between six months to two and a half years junior in relation to the authors. The authors sought continual feedback over the years in order to modify and improve the pedagogical methods to be of better relevance. Also, over the years, the modules were shortened significantly but made more frequent, as it was found that it was almost impossible to spend more than 45 minutes to an hour learning about postgraduate level statistics due to primary and recency effect. A further addition was also implemented, where during subsequent sessions a five-minute refresher of the past week's lessons would be done, also by one of the trainees. Each session would then also end with a five-minute peer-led assessment, summarization and reflection.

\section{Discussion}

Over the years, the feedback was that a peer-driven teaching model was a valuable addition to the existing biostatistics curriculum. It does not supplant, but rather, enhances existing lecturer-driven education. This was because peers from earlier batches were more in touch with the practical and assessment requirements of learning statistics. Students were more likely to pick up information if they were informed that it would assist in passing an exam, and they were more likely to pick up tips about passing exams when they came from fellow students who had already passed.

Through the peer-driven approach, it was found that most of the students agreed that there were remarkable changes and they were able to comprehend these difficult subjects much better, learning from someone who have "been there, done that". This is consistent with models of adult learning where adult learners are more motivated to learn when it is perceived as relevant and builds on their previous experiences (Spencer, J.A. et. al., 1999). Also peer-driven programmes were helpful as less jargon was used. This is elaborated by Lockspeiser et al as due to increased "cognitive congruence" between near-peer educators and teachers (Cate, O.T. et. al., 2007), as they share a similar knowledge base, and hence can pitch teaching to trainees' similar standards (Lockspeiser, T.M. et. al., 2008).

This is fairly consistent with existing literature that shows that peer-driven learning is helpful in selected contexts (Yu, T.C. et. al., 2011). The General Medical Council in the UK in fact explicitly states that "medical graduates must function as educators" (GMS et. al., 2010), and medical schools in the UK are already adopting pilot projects to that effect (Jackson, T.A. et. al., 2012). In the long run, this is important as doctors will have to hold teaching roles (Dandavino, M. et. al., 2007). Specifically, psychiatry trainees will become psychiatrists who will be expected to be able to educate both their patient through psychoeducation within clinical consultations, and the general public through awareness talks. Hence peer-led education is a good start in developing those skills in the long run. Moreover, there is of course consensus that peer-driven teaching also refines the knowledge of the teacher through reflective learning (Tang, T.S. et. al., 2004). 
This concurs better with international efforts to move towards student-centred and problem-based learning, and encourages students to take charge of their own education rather than wait to be spoon-fed by lecturers. This also indirectly helps boost their retention, as peer-driven models by definition involve newly educated peers repeating their newfound information back to other peers, thus reinforcing the registration pathways due to repeated use (Cate, O.T. et. al., 2007). Through this process also, peers learn the valuable lesson of working together as a team to surmount obstacles of understanding and application (Evans, D.J.R. et. al., 2009). This is a lesson that doctors today will need to carry forward to their careers, as patient care is always best optimized when a multidisciplinary rather than solitary approach is practiced.

\section{Conclusion}

As conclusion, we would like to suggest peer-driven teaching of postgraduate clinical specialist trainees who are simultaneously serving in hospitals during training and are unable to devote full-time attention to learning biostatistics and epidemiology. Future research to develop systematic peer-led pedagogical approach should be considered to advance medical education delivery. Comparison between the peer-driven and lecturer-driven educational style, similar to the comparison between module-based and subject-based medical education, would also be of great interest in defining future academic syllabus and producing better medical graduates.

\section{References}

Ahmad, Z., Jaafar, R. (1999). Career Choices of Physicians in Malaysia. J. Heal Transl. Med., 4(1), 47-50. https://jummec.um.edu.my/article/view/4432/2236

Baharudin, A., Jaafar, N.R.N., Sidi, H. (2009). Knowledge in Statistic and Epidemiology among Malaysian Postgraduate Students: Is It Difficult for Our Trainees to Perform on the Mock Critical Review Paper? ASEAN J. Psychiatry, 10(1), 1-13.

http://citeseerx.ist.psu.edu/viewdoc/download?doi=10.1.1.385.3616\&rep=rep1\&type=pdf

Cate, O.T., Durning, S. (2007). Peer Teaching in Medical Education: Twelve Reasons to Move from Theory to Practice. Med. Teach., 29(6), 591-599. https://www.tandfonline.com/doi/abs/10.1080/01421590701606799?journalCode=imte20

Dandavino, M., Snell, L., Wiseman, J. (2007). Why Medical Students Should Learn How to Teach? Med. Teach., 29(6), 558-65.

https://www.tandfonline.com/doi/abs/10.1080/01421590701477449?journalCode=imte20

Evans, D.J.R., Cuffe, T. (2009). Near-Peer Teaching in Anatomy: An Approach for Deeper Learning. Anat. Sci. Educ., 2(5), 227-233.

https://anatomypubs.onlinelibrary.wiley.com/doi/abs/10.1002/ase.110

GMS (General Medical Council). Tomorrow's Doctors: Recommendations on Undergraduate Medical Education, London, 1993.

http://explore.bl.uk/primo_library/libweb/action/display.do?tabs=moreTab\&ct=display\&fn=se arch\&doc $=$ BLL01012384014\&ind $=1 \&$ recIds $=$ BLL01012384014\&recIdxs $=0 \&$ elementId $=0 \&$ renderMode $=$ poppedOut $\&$ displayMode $=$ full $\&$ frbrVersion $=\&$ frbg $=\& \& d s c n t=0 \&$ scp. scps $=$ scop e\%3A\%28BLCONTENT\%29\&vl(2084770704UI0) $=$ any \&tb=t\&vid=BLVU1\&mode=Basic\&s $\mathrm{rt}=\mathrm{rank} \& \mathrm{tab}=\mathrm{local} \_\mathrm{tab} \& d u m=\operatorname{true} \& \mathrm{vl}($ freeText 0$)=\mathrm{m} 02 \% 2 \mathrm{~F} 33982 \& \mathrm{dstmp}=1608594581546$ 
Jackson, T.A., Evans, D.J.R. (2012). Can medical Students Teach? A Near-Peer-Led Teaching Program for Year 1 Students, Adv. Physiol. Educ., 36(3), 192-196.

https://journals.physiology.org/doi/full/10.1152/advan.00035.2012?rfr_dat=cr_pub++0pubmed \&url_ver=Z39.88-2003\&rfr_id=ori\%3Arid\%3Acrossref.org

Lockspeiser, T.M., Sullivan, P.O., Teherani, A., Muller, J. (2008). Understanding the Experience of Being Taught by Peers: The value of Social and Cognitive Congruence. Adv. Heal. Sci. Educ. Theory Pract., 13(3):361-372. https://link.springer.com/article/10.1007/s10459-006-9049-8

Salim, H., Lee, P.Y., Ghazali, S.S., Ching, S.M., Ali, H., Shamsuddin, N.H., Mawardi, M., Kassim, P.S.J., Dzulkarnain, D.H.A. (2018). Perceptions toward A Pilot Project on Blended Learning in Malaysian Family Medicine Postgraduate Training: A Qualitative Study, BMC Med. Educ., 18(1), 206(1-10). https://bmcmededuc.biomedcentral.com/articles/10.1186/s12909-018-1315-y

Sidi, H., Puteh, S.E.W., Rahman, F.N.A. (2008). Malaysian Postgraduate Training in Psychiatry: Are Our Trainees Having Consistent Problem in Basic Science? ASEAN J. Psychiatry, 9(1), 6-13. http://www.myjurnal.my/public/article-view.php?id=62963

Spencer, J.A., Jordan, R.K. (1999). Learner Centred Approaches in Medical Education. BMJ, 318(7193), 1280-1283. https://www.bmj.com/content/318/7193/1280.1

Tang, T.S., Hernandez, E.J., Adams, B.S. (2004). Learning by Teaching: A Peer-Teaching Model for Diversity Training in Medical School, Teach Learn Med., 16(1), 60-63. https://www.tandfonline.com/doi/abs/10.1207/s15328015tlm1601_12

Yong, F.L. (2010). A Study on The Cultural Values, Perceptual Learning Styles, and Attitudes Toward Oracy Skills of Malaysian Tertiary Students. Eur. J. Soc. Sci., 13(3), 478-492. http://www.eurojournals.com/ejss_13_3.htm

Yu, T.C., Wilson, N.C., Singh, P.P., Lemanu, D.P., Hawken, S.J., Hill, A.G. (2011). Medical Students-as-Teachers: A Systematic Review of Peer-Assisted Teaching During Medical School. Adv Med Educ Pract., 2011(2), 157-172. https://www.dovepress.com/medicalstudents-as-teachers-a-systematic-review-of-peer-assisted-teac-peer-reviewed-article-AMEP 